\title{
Neuroeconomics as a Natural Extension of Bioeconomics: The Shifting Scope of Standard Economic Theory
}

\author{
JACK J. VROMEN \\ Philosophy Department, Erasmus University, Rotterdam, 3000 DR, The Netherlands \\ (Vromen@fwb.eur.nl)
}

\begin{abstract}
Synopsis: Neuroeconomics rightly has been claimed to be a natural extension of bioeconomics. One of the things bioeconomics investigates is what behavioral dispositions and what behavioral patterns evolutionary processes have produced. Neuroeconomics extends this to the study of evolved mechanisms that are at work in decision-making at the neural level of the brain. The paper argues that in another respect neuroeconomics and bioeconomics are discontinuous, however. Bioeconomics maintains that the applicability of standard economic theory's constrained maximization framework is not confined to human behavior. The constrained maximization framework is believed to be suitable to describe behavior throughout the animal kingdom. By contrast, despite some minor internal disagreements all neuroeconomists seem to agree that human behavior is predicted poorly by standard economic theory in several social and economic situations. Neuroscience is believed to hold out the hope of an advanced understanding of when and why this is the case.
\end{abstract}

Key words: constrained maximization, evolutionary biology, natural selection, neuroscience

JEL classification: A12, B25, B52

\section{Introduction}

Neuroeconomics has been claimed to be a natural extension of bioeconomics (Zak 2004). And, indeed, neuroeconomics can be said to carry on a line of research suggested by, but not actively pursued in bioeconomics. One of the things bioeconomics is keenly interested in is what behavioral rules and dispositions processes of biological evolution have equipped us with. The leading idea here is that studying the phylogenetic history of Homo sapiens helps us identify and understand better the behavioral rules and dispositions that still guide human behavior. Neuroeconomics similarly is mainly interested in identifying evolved processes and mechanisms underlying behavior. Several sophisticated brain scanning techniques have become available that enable neuroscientists to track brain activity directly at the neural level. The fact that both bioeconomics and neuroeconomics concentrate on the significance of past evolutionary processes for studying current behavior sets them apart from other attempts to relate evolution (and evolutionary 
theory) to economics, such as evolutionary game theory (see, for example, Maynard Smith 1982, Weibull 1995, Samuelson 1997, Young 1998) and (Nelson \& Winter-type) evolutionary economics (after Nelson \& Winter 1982; see also, for example, Hodgson 2000, Metcalfe 1998, Loasby 1999, Dopfer 2005). These latter theories (or rather projects) conceive of ongoing economic processes as evolutionary processes (Vromen 1995, 2004a,b). In doing so, scant attention is paid to the fact that human beings are evolved creatures and to the implications this has for studying current human behavior. ${ }^{1}$

As will be argued in detail below, however, there is one important respect in which neuroeconomics cannot be regarded as a natural extension of bioeconomics. Bioeconomists seem to hold that standard economic theory's assumption that individuals are constrained maximizers is applicable to behavior of all evolved creatures across the animal kingdom. While this assumption should be understood metaphorically in case of the behavior of evolved non-human animals, it is taken by bioeconomists to give a (at least approximately) literally true depiction of human decision-making in the economic realm. Although neuroeconomists surely do not deny the usefulness of applying standard economic theory to study brain processes at the neural level, they do not hold that standard economic theory adequately explains human decision-making and correctly predicts human behavior in all contexts. Contemporary neuroscience suggests that large and significant chunks of human behavior (including important parts of economic behavior) are automatic and affect-driven rather than under 'cool' conscious control. Furthermore, neuroeconomists acknowledge the existence and significance of anomalies, human behavior displayed in experiments that deviate from standard economic theory's predictions. Instead of embarking on ingenious attempts to rationalize these anomalies away, neuroeconomists invest high hopes in the potential of neuroscience to facilitate the development of a more general economic theory that is able to explain not only when (in what sorts of conditions) and why people display behavior that is consistent with standard economic theory's predictions, but also when and why anomalies occur.

\section{Bioeconomics}

What is bioeconomics? The general idea seems to be that the disciplines of evolutionary biology and of economics are somehow to be more closely connected. But how is this supposed to take place and what purpose is served by it? In the inaugural issue of the Journal of Bioeconomics, Landa \& Ghiselin (1999) argue that bioeconomics began with the early pioneering work of Tullock (1971a,b), Ghiselin (1974, 1978), Becker (1976) and Hirshleifer (1977a,b, 1978). If their work set the scene for bioeconomics, what are the defining and distinguishing features of bioeconomics? 
In Tullock's and Ghiselin's work the emphasis clearly is on what biology can learn from economics. Tullock (1971a) work is an illustration of the fruitfulness of standard economic analysis for the study of biological phenomena (in this specific case the consumption of the Eucosmid moth Ernarmonia conicolana by coal tits). Tullock shows that the existing explanation of the coal tits' consumption behavior in biology can be greatly simplified by treating coal tits as careful optimizing shoppers. ${ }^{2}$ This analogical treatment of the coal tits' consumption behavior is warranted, Tullock argues, because it makes sense to assume that coal tits have inherited reasonably efficient patterns of behavior. After all, if their ancestors did not evolve such patterns, they would not have survived and have left offspring. The only thing that economists can learn from this transfer of their constrained maximization framework to biology, ${ }^{3}$ it seems, is that economic analysis can also be fruitfully applied in the biological realm. Thus for Tullock, bioeconomics seems to mean primarily the application of standard economic theory, and more in particular its behavioral assumption that individuals are constrained maximizers, in studying biological phenomena. ${ }^{4}$

Ghiselin $(1974,1978)$ also focuses on the application of economic concepts and principles such as division of labor, specialization, competition and cooperation in studying biological phenomena (such as the division of labor of teeth in the human mouth). It is boldly claimed that biology (properly understood) is wholly an economic discipline (Ghiselin 1978, p. 233). But unlike Tullock, Ghiselin argues that these economic concepts and principles cannot be directly drawn from standard economic theory. They need some reworking and elaboration before they can illuminate biological phenomena. ${ }^{5}$ What is needed, Ghiselin argues, is the development of general economy. Once general economy is developed, as a single branch of knowledge, biology and economics will be seen to study two different areas of it. Economics studies political economy (in which institutions like law and property rights regulate competition), whereas biology studies natural economy (in which competition is not regulated by formal institutions).

Both Tullock and Ghiselin acknowledge that at least up till the twentieth century, there has been an incessant transfer of ideas, concepts, principles and tools from economics to biology. The most famous and probably also most significant example, of course, is the influence of Malthus's population thinking (based on the notion of 'crowding and struggle') and Adam Smith's notions of unintended consequences and the invisible hand on Darwin's (and Wallace's) development of the notion of natural selection as the key principle to organize all the empirical data gathered in his voyages with the HMS Beagle (Schweber 1968). Tullock also observes that ever since Darwin's The Origin of Species, the biological analogue of constrained maximization (or optimization), adaptation, has been part and parcel of (evolutionary) biology. With a few exceptions (notably Hamilton's and Trivers's work and the work in foraging theory and behavioral ecology done by people like Charnov and Krebs, that paved the way for Wilson's Sociobiology), ${ }^{6}$ however, the constrained maximization framework remained hidden and implicit in biology. It 
is clear that especially Tullock holds that biology could profit from a more explicit and wholesale adoption of the constrained maximization framework.

Things seem to be somewhat different with Becker and Hirshleifer. They too identify already existing structural similarities between economics and biology and they too believe that incorporating more economic concepts and tools could further enrich biology. But in addition to this, Becker and especially Hirshleifer hold that, conversely, economics can be enriched by incorporating insights from evolutionary biology. ${ }^{7}$ Their model of bioeconomics is one of biology and economics mutually enriching each other. Like Tullock, Becker and Hirshleifer argue that biology can gain from an explicit and consistent use of standard economic theory's constrained maximization framework. Unlike Tullock, Becker and Hirshleifer maintain that conversely economics can benefit from accommodating insights from biology. What evolutionary biology can contribute to economics is the insight that individual human agents belong to the evolved species of Homo sapiens and that their current behavior reflects (or bears the stamp of) the phylogenetic evolution of their species. More in particular, evolutionary biology can help economists in identifying (basic) preferences (or preference patterns) in a non-arbitrary and explicable way. As Hirshleifer (1977a, p. 18) puts it, 'the programmatic contention here is that such preference patterns, despite seemingly arbitrary elements, have survived because they are mainly adaptive to environmental conditions. ${ }^{8}$

Becker's (1976) well known economic treatment of the evolution of altruism seems to have been a major source of inspiration for Hirshleifer's vision of biology and economics mutually enriching each other. Becker sets out to show that altruism can evolve by other means than 'group selection'. In their attempt to answer their central theoretical problem of how altruism can possibly evolve (Wilson 1975 , p. 3) sociobiologists are said to invoke 'group selection'. A particular variant of 'group selection', Becker argues, is kin selection. ${ }^{9}$ If individuals are genetically related to a sufficient degree, then seemingly self-sacrificing behavior of an individual can contribute to the propagation of that individual's genes in the population's gene pool. Such models are unnecessary, Becker argues. Bringing in 'individual rationality', the assumption that individuals maximize utility functions subject to limited resources, suffices to show that altruism toward non-kin can evolve by natural selection (Becker 1976, p. 818). What Becker shows in particular is that although altruists seem to be left with less wealth and consumption than an otherwise equally able egoist almost by definition, ${ }^{10}$ a fuller analysis of the interaction between rational individuals points out that this need not be so. Altruists may wind up with more wealth and consumption and this is exactly why altruism has survival value.

Without going into all of the details of Becker's 'fuller analysis', some elements warrant further attention here. As Becker (1976, p. 820) himself observes, for altruistic 'Big Daddy' to wind up with more wealth and consumption than an equally able egoist, a crucial assumption is that egoistic 'Rotten Kid' correctly anticipates Big Daddy's response to its behavior. ${ }^{11}$ Only if Rotten Kid correctly 
anticipates Big Daddy's response is it willing to transfer some of its wealth to Big Daddy (knowing that in return Big Daddy's transfer will more than compensate for that, so that in the end Rotten Kid is better off than without initially transferring some of its income to Big Daddy). Only then does egoistic Rotten Kid behave 'as if' he, like Big Daddy, were also altruistic (p. 820 and p. 822). Here we see the crucial role played by the behavioral assumption of individual rationality. As Hirshleifer (1977a, p. 26) notes, the insight of standard economic theory that biology should take to heart is that in certain circumstances even egoists cooperate. Instead of assuming that behavior directly reflects the individual's preferences (or 'drives', or 'instincts', as biologists use to call them, for Hirshleifer, individual behavior is always determined by preferences and constraints (or opportunities) in conjunction. ${ }^{12}$ Egoists need not always behave 'egoistically' in a non-cooperative way. Under suitable constraints rational egoists will choose to behave in 'nonegoistic' cooperative ways.

Although Hirshleifer remarks that the assumption of 'real' conscious maximizing may be sometimes inappropriate in economics (and that in such cases, the assumption of satisficing may be the better alternative), there is no evidence that he thinks that there are serious problems with the application of the constrained maximization framework in economics. This seems to be shared by other proponents of bioeconomics: no one seriously considers the possibility that bringing insights from biology to bear on economics can undermine or delimit the applicability of the constrained maximization framework in economic theory's traditional domain. It may be that taking biological insights seriously may necessitate economists to extend the terms in utility functions. But the possibility that the constrained maximization framework itself might be put in jeopardy by taking biological findings into account is something no one seems to take seriously.

Summing up now, what is bioeconomics? If we look at how individual pioneers actually implement the bioeconomics project, we see interesting differences. For Tullock and Ghiselin doing bioeconomics is largely an exercise in showing the fruitfulness of using economic concepts, techniques and approaches in biology. ${ }^{13}$ For Becker and Hirshleifer practicing bioeconomics ideally enriches both biology and economics. This implies a transfer also in reverse direction: insights from evolutionary biology are to be incorporated into economic theory. The prevailing sentiment here seems to be that what economics can learn from biology should move beyond mere analogy and metaphor. Individual human beings are evolved creatures and their decision-making betrays the evolutionary history of their species. Becker's version of bioeconomics seems to be the most clearly and narrowly delineated. Biologists are advised to take more notice of standard economic theory's constrained maximization framework and to apply it more explicitly and consistently. Vice versa, evolutionary biology can help economists in identifying basic preferences of economic agents in a non-arbitrary way. 


\section{Neuroeconomics as a natural extension of bioeconomics}

Neuroeconomics is a booming business these days. Worldwide, more than a dozen of new Centers for Neuroeconomics Studies equipped with high tech brain scans (using techniques such as PET and fMRI) have been founded just within the past few years. ${ }^{14}$ Neuroeconomics gets quite some coverage both in prestigious academic journals (see, for example, Camerer 2003b and Glimcher \& Rustichini 2004) and in the popular press. ${ }^{15}$ What is neuroeconomics? Zak (2004, p. 1737) argues that 'Neuroeconomics is a natural extension of bioeconomics. [...] The bioeconomics research programme uses evolutionary biology to build models that predict human behavior [...] Whereas bioeconomics has focused primarily on ultimate causes of behavior [...], the neuroeconomics research programme seeks to discover proximate causes of choice behavior.' I think this is quite right. Both bioeconomics and neuroeconomics take recourse to evolutionary biology in building models of human economic behavior. But neuroeconomics shifts the focus from ultimate to proximate causes of behavior. While ultimate causes refer to evolutionary forces and pressures occurring prior to the lifetimes of the individuals whose behavior we want to explain, proximate causes occur within the individuals' lifetimes (Mayr 1961). Bioeconomists concentrate on studying past processes of natural selection, as the alleged major force driving biological evolution, and its consequences for current behavior. Neuroeconomists investigate how current behavior is caused by ongoing brain processes (or, more general, processes in the nervous system). ${ }^{16}$

For the pioneering bioeconomists Tullock, Ghiselin, Becker and Hirshleifer the major ultimate cause driving biological evolution clearly is natural selection. ${ }^{17}$ What is behind their plea to use standard economic theory's constrained maximization framework more explicitly and extensively in evolutionary biology is the insight that constrained maximization of (inclusive) fitness mimics outcomes of processes of natural selection. If natural selection holds sway, nature behaves as if it were optimizing the (inclusive) fitness of individuals. It is furthermore taken for granted that while more primitive life forms cannot engage in deliberate and conscious optimizing (or constrained maximization), we humans can. That is why a literal application of the framework is warranted only in the case of human behavior. Standard economic theory's constrained maximization framework can also be used to study the outcomes of natural selection for the behavior of animals (other than humans), but then the framework is to be understood metaphorically. This suggests that bioeconomists are not completely silent on proximate causes of current behavior. They identify preferences and opportunities (and, it might be added, expectations) as proximate causes of current behavior. As Hirshleifer (1977a) insists, for example, behavior is always the outcome of the preferences in combination with opportunities (or constraints), and never of preferences alone. Thus, all allusions to 'as-if optimizing' notwithstanding, bioeconomists do seem to believe that individual human beings actually act on their preferences, opportunities and expectations and that they do so more or less rationally. ${ }^{18}$ 
Neuroeconomists seek to identify proximate causes at a different level of organization (or, more neutrally, of description). The preferences and expectations that bioeconomists focus on are mental states to be located at the level of the human mind. Neuroeconomists concentrate on proximate causes at the level of the anatomy and physiology of the human brain. ${ }^{19}$ Exactly how states, entities and their properties at these two levels, the level of the human mind and that of the human brain, are related to each other is a perennial issue in philosophy. Arguably this issue is still unresolved and looming large in philosophy of mind. As we shall see, what is also still an open, unresolved issue is what implications our improved understanding of neural processes and mechanisms has for how decision-making in the brain proceeds and for how rational human behavior is.

Within neuroeconomics we encounter a tension that is reminiscent of the tension we found within bioeconomics. We saw that some bioeconomists hold that bioeconomics involves a one-way transfer of economic concepts and principles to evolutionary biology, from which theorizing in evolutionary biology, and in evolutionary biology only, is meant to benefit, while others maintain that bioeconomics is a two-way transfer of economic principles and biological insights, from which theorizing in both economics and evolutionary biology are meant to benefit. Likewise, there are some neuroeconomists, such as Glimcher and Berns, who hold that neuroeconomics involves making use of economic theories in neuroscience, from which theorizing in neuroscience is to benefit. It is telling that instead of neuroeconomics, Berns (2003) and Montague \& Berns (2002) speak of neural economics: the economics of neural activity. But there are also some neuroeconomists, such as Camerer, Loewenstein \& Prelec, who believe that neuroeconomics primarily involves the reverse transfer of bringing in insights from neuroscience into economics, from which economic theorizing is to benefit. The former sort of neuroeconomists pursues a reformist or revisionist (if not revolutionary) program within neuroscience, whereas the latter group pursues a reformist program within economics. ${ }^{20}$

This tension within neuroeconomics need not reflect major substantive disagreements, of course. Whether neuroeconomics is intended to improve theorizing in neuroscience or in economics, all protagonists might agree on the same particular view on the brain processes underlying human decision-making and human behavior. And this arguably is what all neuroeconomists are ultimately interested in. In the end, enhanced understanding of the processes and mechanisms underlying behavior is what they are all after. Quarrels about disciplinary boundaries and about the scope of economic theories arguably are of secondary importance only. So let us focus on the more interesting substantive issue of whether all neuroeconomists concur on roughly the same view on human behavior and human decision-making. At first sight it seems that here too there are significant differences and disagreements. As will be discussed in more detail shortly, especially Glimcher et al. (2005) explicitly distance themselves from the view expounded by Camerer et al. $(2004,2005)$ about brain architecture and brain functioning on the one hand, 
and various forms of rational and irrational behavior, on the other. ${ }^{21}$ It seems that the main difference in view between the two groups can be put in the following general terms. Neuroscientists such as Glimcher and Berns stress that standard economic theories, such as expected utility theory and game theory, turn out to be remarkably well-suited to describe neural activity in specific subsystems in the human brain. In contrast, behavioral economists such as Camerer and Loewenstein tend to emphasize when and why such standard economic theories go wrong in predicting human behavior. Thus whereas the one group seems to stress the usefulness of standard economic theories for understanding behavior, the other group seems to emphasize the limits of those theories for understanding behavior.

\section{Neuroeconomics Glimcher et al. style and neuroeconomics Camerer et al. style}

The neuroscientist Glimcher (2003) turns to economics (especially expected utility theory and game theory) to go beyond the prevailing reflexological paradigm in neuroscience. Glimcher argues that the reflexological (or reflex-based) paradigm, that goes back to Sherrington (and even further back to Descartes) and that essentially conceives of the working of the nervous system in terms of the minimal set of neurobiological components that could account for an elementary behavior (a reflex), has been extremely useful for describing relatively simple sorts of behavior. But it has problems with understanding how larger systems of such components accomplish more complex tasks. The reflexological approach misses out on mutual interactions between the components and feedback loops from the environment that are crucial to their performance. According to Glimcher, David Marr's (1982) computational approach, which in essence is a rudimentary form of economic analysis, shows the way to overcome this shortcoming. Any attempt to understand information-processing systems such as brains, Marr argues, should start with a specification of the task, or computational goal, that the system evolved to perform. Glimcher argues that expected utility theory and game theory provide natural extensions of Marr's approach.

First attempts to apply those theories to study the working of the brain (such as Platt \& Glimcher 1999) yielded fascinating results. It is not just that at the aggregate (population) level, actual behavior often approximates predictions of economics to a surprising high degree. Empirical evidence seems to suggest that even monkeys display the seemingly sophisticated patterns of mixed equilibriums predicted by game theory, for example. The really remarkable thing is that at the level of individual neurons (or small groups of neurons) neural firing rates seem to track changes in probabilities and values. Glimcher argues that the calculations ascribed to rational individuals in, for example, expected utility theory - first computing the relative desirability of each possible course of action and, second, selecting the most desirable one - are literally executed at the neural level: 
'Neoclassical theory has always made the famous as if argument: it is as if expected utility was computed by the brain. Modern neuroscience suggests an alternative, and more literal, interpretation. The available data suggest that the neural architecture actually does compute desirability for each available course of action. This is a real physical computation, accomplished by neurons, that derives and encodes a real variable. The process of choice that operates on this variable then seems to be quite simple: it is the process of executing the action encoded as having the greatest desirability' (Glimcher et al. 2005, p. 8). ${ }^{22}$

It seems that Glimcher's modern neuroscience, rebuilt on modern economic theory as its basis, revives a forlorn hope among economists that the human brain can be shown to harbor a hard-wired Benthamite hedonistic pain - pleasure calculus. For more than a century economists did not dare to hope that the calculations and computations ascribed in economic theory to individuals could really be observed and measured inside the heads of individuals. But now it seems that utility functions are not merely convenient theoretical constructs but are observable physiological realities (Zak 2004). ${ }^{23}$ As Powell (2003, p. 314). puts it, 'at the level of neurons, we might all be math-whizzes.'

Glimcher's version of neuroeconomics seems to be reminiscent of Tullock's and Ghiselin's version of bioeconomics in that it is a plea to use economic analysis in biology (this time neurobiology, not evolutionary biology). Like Tullock and Ghiselin, Glimcher argues that standard economic analysis is useful to describe the behavior of non-human animals such as monkeys. But Glimcher seems to go beyond Tullock and Ghiselin in suggesting that economic analysis is not only useful to describe outcomes of natural selection (as the supposedly dominant ultimate cause underlying evolved behavior). Glimcher seems to hold that expected utilities are actually computed within individuals as proximate causes of their behavior. At the neural level, constrained maximization is taking place in both human and (at least a few) non-human animals.

The version of neuroeconomics presented by Camerer et al. $(2004,2005)$ seems to be quite different. The turn of these behavioral economists (or behavioral game theorists; Camerer 2003a) to neuroscience seems to be primarily motivated by the desire to overcome perceived weaknesses and shortcomings of standard economic theory (including standard game theory). They hope that neuroscience helps us understand better why standard economic theory has such a limited or even poor predictive success. Camerer et al. are primarily concerned with explaining anomalies, behavior found in experimental psychology and in behavioral economics that run counter to standard economic theory's predictions. Given their background in behavioral economics, it comes as no surprise that Camerer et al. are also interested in the issue whether people are the 'cool' calculating maximizing creatures that standard economic theory takes them to be, or are rather led by their 'hot' emotional states and by simple heuristics. Do people most of the time go through the time-and-energy-consuming search and decision-making processes ascribed to 
them by standard economic theory? Or do they rather rely (on 'the automatic pilot') on shortcuts, such as rules of thumb and on their 'gut feelings'?

After surveying the relevant literature, Camerer et al. argue that automatic (that is, not consciously controlled) behavior is the default mode of operation in human behavior and that affect (rather than cognition) is primary in driving human behavior. In contrast to consciously controlled behavior, automatic behavior typically occurs without awareness, is accompanied by a subjective feeling of effortlessness, is reflexive (that is, not evoked deliberately) and is not introspectively accessible. ${ }^{24}$ Due to the latter feature the causes behind most of our behavior elude us. Attempts to access these causes can be made and are often made, but are most likely to lead to spurious sense-making. Attempts can also be made to override automatic, affect-driven behavior cognitively. But such attempts happen less frequently than we wish to think and are often not successful (like countering our longing for calorie-rich food in a diet). Camerer et al. conclude that since on the narrow technical understanding of 'rational behavior' in standard economic theory only consciously controlled cognitive-driven behavior is rational, current neuroscience suggests that most of human behavior is not covered by standard economic theory.

Camerer et al. pretty much take for granted that neuroscience has already produced insights and results that economists can only ignore at their own peril. Taking neuroscience's insights and results to heart, they argue, would call for a drastic revision of standard economic theory. Their message seems to be opposite to Glimcher's. This impression is strengthened by Glimcher et al.'s criticism of Camerer et al's depiction of the human brain. Glimcher et al. (2005) explicitly take sides against Camerer et al. $(2004,2005)$ in arguing that the latter erroneously assume that different anatomical areas in the brain are responsible for rational and irrational decision making respectively. Camerer et al. wrongly take rational decision-making to be the product of the cerebral cortex, Glimcher et al. argue, as they mistakenly believe that rational decision-making involves conscious introspection and (again mistakenly) that conscious experience resides uniquely in the cerebral cortex. There is no neurobiological evidence supporting this view, Glimcher et al. (p. 40) argue. They go on arguing that the essentially dualistic picture of brain functioning that Camerer et al. paint, in which simpler and cruder mechanisms are held responsible for irrational behavior, fits the prevailing reflexological paradigm well. In the alternative monistic picture favored by Glimcher rational decision-making can be going on across various anatomical areas of the brain.

Thus it seems that there are significant substantive differences between the two versions of neuroeconomics. Whereas Glimcher et al. stress rational behavior, in human and non-human animals alike, Camerer et al. emphasize various forms of irrational human behavior. And while Camerer et al. maintain that insofar as humans are capable of rational behavior this is due to the prefrontal cortex, Glimcher et al. argue that the brain areas that are (causally) responsible for 
rational behavior are not confined to the prefrontal cortex but are distributed all over the entire brain.

\section{Disagreements within neuroeconomics that might be apparent rather than real}

Yet upon closer inspection the disagreements between these two versions are less profound than they at first seem. Differences are partly 'semantic', are more a matter of emphasis and of degree than of real substance and stem to some extent from the fact that the main protagonists have different battles to fight within their own disciplines.

Contrary to what both Glimcher et al. suggest, there does not seem to be a big difference in opinion on the issue of brain functioning. While Glimcher et al. are right that Camerer et al. argue that there is functional specialization in the brain's architecture, one of the things that Camerer et al. emphasize is that many sorts of behavior typically involve several areas in the brain. Sometimes different areas collaborate with each other, sometimes they compete with each other, but only rarely is just one area implicated in producing behavior. Furthermore, Glimcher is not denying that, at the anatomical level of organization, the brain (and more generally, the nervous system) has a modular structure. On the contrary, this is presupposed in Glimcher's own research. Platt \& Glimcher's (1999) path-breaking study of eye movements in monkeys, for example, presupposes prior knowledge of the principal pathways (the anatomical regions in the brain that are subsequently activated) in visual processing. If this knowledge were lacking, we would not know where to look for neural activity when an organism is performing a specific task.

What Glimcher is suggesting is that at the level of neural activity there is maximization of expected utility throughout many regions of the brain. This is fully compatible with Camerer et al.'s statement that automatic, affect-driven behavior is the default and primary mode of operation of the brain. All the computing and calculating at the neural level stipulated by Glimcher can be accompanied by a feeling of effortlessness on the part of the acting (or active) individual, for example. Glimcher et al. are clearly not suggesting that neural activity can only be evoked consciously and deliberately! How tempting (and perhaps even how 'natural') it is to misunderstand what Glimcher is arguing, is inadvertently but nicely illustrated by Camerer. Camerer (2005) argues that if people like Glimcher are right in claiming that expected utility maximizing is literally taking place in the brain, then next to two processes of tracking the desirabilities and probabilities of different courses of action, there must also be a third process of combining these in selecting the optimal course of action: "If this theory [the "rational choice" approach] is correct, neuroeconomics will find two processes in the brain - one for guessing how likely one is to win and lose, and another for evaluating the hedonic pleasure 
and pain of winning and lose - and another brain region which combines probability and hedonic sensations.'

But this is surely not what Glimcher et al. are arguing. Glimcher is not postulating the existence of something like a homunculus in the brain that, like a miniature microscopic version of a person in the brain, gathers information about utilities and probabilities of all courses of action and that subsequently figures out what is the best (or optimal) course of action on the basis of this information. When Glimcher et al. argue that the calculations described in expected utility theory are literally executed at the neural level, they do not imply that neurons conduct the sort of mental operations that we ascribe to persons. There are no neurons in the brain that, like agents writ small, engage in a conscious and deliberate attempt to select the option with highest expected utility. Selection of the course of action that actually is displayed rather proceeds in a purely mechanical way (in a 'winner-takeall' fashion; Glimcher \& Rustichini 2004, p. 452).

Once we carefully distinguish between different levels of organization (or of description, or of analysis), we see that much of the alleged disagreement between the two versions is apparent rather than real. The computations that Glimcher et al. describe at the neural level should not be conflated with the things that are going on at the level of the human mind. If we try to solve equations in a math exercise, for example, the calculations we do are evoked deliberately (we want to solve the equations and therefore we perform the necessary calculations) and are accompanied with a subjective feeling of effort put into them. These subjective mental experiences can be totally absent when the computations at the neural level, described by Glimcher et al., are executed. ${ }^{25}$ Camerer et al. claim that automatic behavior (rather than consciously controlled action) is the default mode of operation in human behavior. One of the typical features of automatic behavior is that it is accompanied by a subjective feeling of effortlessness. Appearances notwithstanding, this claim of Camerer et al. is compatible with Glimcher et al.'s claim that groups of neurons track (changes in) expected utilities of options. It might be true both that, at the neural level, desirabilities and probabilities are computed and that at the mental level, no conscious and deliberate effort is made by the individuals in question to calculate desirabilities and probabilities.

What the foregoing discussion also makes clear is that Glimcher et al. and Camerer et al. entertain different understandings of what 'rational behavior' means in economic theory. For Glimcher et al. 'rational behavior' essentially means behavior as predicted by economic theories such as expected utility theory and game theory. ${ }^{26}$ On this understanding, whether or not the behavior is arrived at through conscious deliberation on the part of the acting individuals is irrelevant. The fact that Camerer et al. argue that standard economic theory fails to cover automatic and affect-driven behavior reveals that on their understanding one of the things that 'rational behavior' in economic theory implies is that the behavior is arrived at through conscious deliberation. While on the understanding of Glimcher et al. making use of economic theory is silent and neutral about the sort 
of processes at the mental level that generate behavior, on the understanding of Camerer et al. economic theory implies a particular view of such processes. These two understandings should not be confused with one another. In fact, Glimcher et al.'s research illustrates that behavior predicted by economic theory need not be arrived at through conscious deliberation.

\section{Substantive agreements within neuroeconomics}

We saw that Glimcher et al's claim that (changes in) desirabilities and probabilities are computed at the neural level and Camerer et al's claim that automatic, rather than consciously controlled behavior is the default mode of behavior need not necessarily conflict with each other. Desirabilities and probabilities can be 'rationally' computed at the neural level when the actual mode of operation of the individuals in question is automatic. It is perfectly possible that 'irrational behavior', in the one sense of not being consciously pre-meditated, is 'rational behavior' in the other sense of behavior that is consistent with standard economic theory's predictions. ${ }^{27}$ Indeed, insofar as individuals display rational behavior in this latter sense, then it must be the case that at some level of description somehow and somewhere (changes in) the relevant variables must be tracked by and in the individuals. Seen in this light, results as those obtained by Platt \& Glimcher (1999) should not be that surprising to us.

The fact that the two groups need not disagree at this point does not imply, of course, that they do not disagree at other points. The fact that Glimcher et al. focus on behavior that is consistent with standard economic theory's predictions, while Camerer et al. pay more attention to anomalies, forms of behavior inconsistent with standard economic theory's predictions, might be taken to indicate that both groups disagree about the extent to which human behavior is rational (in the sense of being consistent with standard economic theory's predictions). It might be taken to indicate that Glimcher et al. hold that human behavior is rational to a larger extent than Camerer et al. believe it is. This might indeed be true. And as yet it is an open, unresolved issue as to who is right.

What it is certainly not true, however, is that Glimcher et al. deny that there are significant anomalies in human choice behavior. As a matter of fact, Glimcher et al. do not take for granted that organisms behave as predicted in standard economic theory. It is by no means guaranteed that organisms have evolved mechanisms to fulfill certain tasks optimally. What Glimcher et al. really argue is that using the economic approach enables one to specify the computational goal that individuals have to attain (or rather the computational goal that their ancestors had to attain in order to be reproductively successful), ${ }^{28}$ without taking for granted that the individuals attain this goal efficiently. Economic theory provides an indispensable benchmark (of optimality or efficiency) for further research into the brain (and into any information-processing system in general). Barring such a 
benchmark, it is argued, we do not know what and where to look for in the brain and the prospects of being able to carve the brain at its natural joints are dim. But it is a benchmark that possibly and perhaps even probably is not attained in actual behavior. ${ }^{29}$ What is more, Glimcher suggests that adopting the economic approach is most useful in identifying neural mechanisms if this benchmark is not attained by far. What is revealed then is that certain inherited and selected mechanisms that presumably worked well in the evolutionary environment in which they evolved do not perform well in the current environment. Mechanisms that were well adapted to the past environmental circumstances in which they evolved may well be maladapted to present circumstances. When activated in present circumstances, they 'misfire' and produce suboptimal or inefficient results.

This is exactly what Camerer et al. (2005) also argue when at the end of their lengthy paper they discuss (in a section with the title "Can neuroscience save rational choice economics?') Glimcher's finding that rational choice takes place at the neural level. ${ }^{30}$ Camerer et al. argue that since studies such as Glimcher's use simple tasks which humans (and monkeys) are well-evolved to perform, it should not come as a surprise that rational choice is vindicated here. But, Camerer et al. go on to argue, the most important kinds of economic behavior involve tasks that are much more complex and abstract (such as manipulating abstract symbols). Whether humans have evolved mechanisms to perform such tasks optimally remains to be seen. The mechanisms that humans did evolve might well be maladapted to do this. Camerer et al. $(2005$, p. 63$)$ conclude their discussion with the following suggestion: 'Ironically, rational choice models might therefore be most useful in thinking about the simplest kinds of decisions humans and other species make - involving perceptual tradeoffs, motor movements, foraging for food, and so forth - and prove least useful in thinking about abstract, complex, long-term tradeoffs which are the traditional province of economic theory.' If this suggestion makes sense, economic theory might well be well suited to address (simple) forms of behavior that it initially was not meant to address and ill suited to address the (more complex) forms of phenomena that it was meant to address.

Thus, while Camerer et al. tend to emphasize anomalies in human behavior more than Glimcher et al. do, both groups are in basic agreement that there are many cases and contexts in which the behavior people display is at odds with predictions of standard economic theory. Ironically, the latter might pertain in particular to the sorts of behavior economic theory was traditionally focusing on. A plausible reason why people display 'irrational' economic behavior is that although the neural mechanisms activated by salient cues in the presently prevailing environment might be well-adapted to the previously prevailing circumstances in which they evolved, they are not well-adapted to current circumstances. This does not necessarily imply that neural mechanisms that in principle could produce 'rational' behavior, behavior that is adapted to current circumstances, are lacking in or unavailable to people. It is possible that such 'rational' neural mechanisms are available to people, but that they lay dormant without being activated. Or if 
activated, they might be not strong enough to check and overrule the workings of the neural mechanisms leading to the 'irrational' behavior. Several neural mechanisms (or 'subsystems') within one individual may complement each other in producing behavior, but they might also compete with each other. This might provide the key to understanding why individuals sometimes display irrational behavior even if each neural subsystem that they comprise could be understood as a 'rational economic agent' (Berns 2003). Even if each neural subsystem evolved (and is well-adapted) to perform a certain function, that is, they can make individuals do things that are not in the individuals' best interest. As Ross $(2006,2007)$ argues, for example, the problem with addicted people is not that their dopaminergic reward systems malfunction. On the contrary, the problem is that in a sense their reward system works too well: it hijacks their limbic system and sabotages the systems that (in non-addicted people) might check its influence on their behavior.

No matter how serious they take alleged anomalies to be and no matter how they account for these, in the end neuroeconomists of all stripes seem to be interested in the same thing. Their final aim is to understand and explain when and why individuals do and when and why individuals do not display behavior predicted by standard economic theory. This also holds for the Glimcher et al. group. For them neuroeconomics is a two-stage process. Up till now we only paid attention to the first stage, the stage in which neuroscience is rebuilt on the basis of economic theory. But to them this is not the end of the story. The second stage is to improve economic theory on the basis of the newly rebuilt neuroscience. An improved economic theory is needed, to explain anomalies that standard economic theory is unable to explain. Thus what all neuroeconomists ultimately want to know is in what sorts of conditions, or under what sorts of circumstances, standard economic theory does and does not predict well and why this is so. Neuroeconomists want to contribute to the development of a theory that is at once more general, in the sense of covering all forms of behavior ('rational' and 'irrational' alike) and more explanatory, in uncovering the internal behavior-generating machinery (at the neural level) that standard economic theory treated as a black box, than standard economic theory.

There seems to be a growing consensus that the notion of 'ecological rationality' (Gigerenzer et al. 1999, Landa \& Wang 2001, Smith 2003, Chorvat \& McCabe 2005, Kysar et al. 2006) can provide an explanation of why actual behavior is consistent with standard economic theory's predictions in some sorts of contexts (or environments) while it is inconsistent with the predictions in other sorts of contexts. The idea behind ecological rationality is that it makes more sense to take the match between specific evolved heuristics (or mechanisms) and specific environments (or contexts) as a standard of rationality than some context-insensitive optimality or efficiency criterion. A heuristic that performs well in the one context or environment in which it evolved might perform poorly in another context or environment. What matters is not just the behavior ultimately arrived at. What matters also are the ease, effectiveness and reliability of the process in which the behavior 
is produced. Thus behavior that is irrational, in the sense of not fully attaining some context-insensitive optimality benchmark, might well be ecologically rational if we factor in decision-making costs and take account of the reliability with which satisfactory results are produced. What is implied here also is that specific heuristics are activated (or triggered, or evoked, or elicited) by specific cues in specific contexts or environments. The heuristics that are activated in the one sort of context may well be different from the ones activated in another sort of context. All this makes it intelligible why people behave 'rationally' in the one sort of context, while they behave 'irrationally' in the other sort of context. The reason is that the specific heuristics activated in the former sort of context are well-adapted to that sort of context, while the specific heuristics activated in the latter sort of context are ill-adapted to that sort of context.

\section{Concluding remarks}

Let us take stock. At first sight, the neuroeconomics movement seems to be internally more divided than the bioeconomics movement. All bioeconomists seem to hold that what bioeconomics entails at any rate is the plea for using economic concepts, approaches and/or principles in (evolutionary) biology. By contrast, not all neuroeconomists plea for the use of economic theories in neuroscience. For sure, for neuroeconomists such as Glimcher and Berns, neuroeconomics does seem to amount primarily if not only to the economics of neural activity. But for Camerer et al., for example, neuroeconomics is the reverse use of insights and findings obtained in neuroscience to suggest new underpinnings for economic theories. We furthermore saw that the neuroeconomists Glimcher et al. criticize Camerer et al. for believing that rational behavior cannot be but the result of the functioning of the cerebral cortex. Glimcher et al. argue that rational decision-making can be distributed among several brain regions and that the cerebral cortex is not necessarily involved in it. Moreover, while Glimcher et al. point out that expected utilities are literally computed at the neural level even in monkeys, Camerer et al. stress the limits of standard economic theories, such as expected utility theory, in describing and explaining human behavior.

We also saw, however, that there seems to be quite some agreement on substantive issues in neuroeconomics. The agreement is not confined to shared basic views on brain architecture and brain functioning. Once we clearly distinguish between different levels of analysis and between different notions of rationality, for example, Glimcher et al.'s finding that expected utility maximization is 'literally' taking place at the neural level turns out to be fully compatible with Camerer et al.'s claim that 'cool' conscious deliberation is the exception rather than the rule in human behavior. More important for economics is the fact that there is a basic agreement among all neuroeconomists that standard economic theory faces several anomalies that are real and significant. There might be differences 
in opinion among neuroeconomists about the extent to which human behavior violates standard economic theory's predictions. But no neuroeconomist shares the confidence that bioeconomists have in the ability of standard economic theory to correctly depict individual human behavior. No bioeconomist seems to call into question that the 'constrained maximization framework' does a good job in representing individual human behavior. This is clearly different for neuroeconomists. There is a shared understanding in neuroeconomics that an improved economic theory, that does not rationalize anomalies away but that is rather able to explain when and why they occur, is badly needed and that neuroscience can be of great help in developing such an improved economic theory. All neuroeconomists hold out the hope that a better understanding of mechanisms working at the physiological and anatomical level of the brain enhances our insight into why standard economic theory predicts well in certain situations while it predicts poorly in others.

There are also several open issues that are not resolved yet. As Glimcher's discussion makes clear, there is much that we do not know yet about brain structure and brain functioning and about their relation with overt behavior. Although it is clear that the production of 'rational behavior', in the sense of behavior that is consistent with standard economic theory's predictions, need not involve the cerebral cortex, it is not so clear how many of the other regions in the brain are capable of producing 'rational' behavior. Neuroscientists such as Glimcher and Berns may be right that there are regions in the brain other than that of the cerebral cortex that track (changes in) relevant variables so that rational behavior is displayed. But as yet it is unclear for what regions this holds. What is not settled either is what sorts of seemingly irrational behavior turn out to be rational once decisionmaking costs are factored in. It is true that sometimes it is better and more efficient to have a quick and effortless response to some stimulus than to engage in costly and time-consuming search, even if the quick and effortless response is not fully accurate. But it remains to be seen how much of the alleged irrational behavior can be 'rationalized' in this vein.

An interesting question (and for economists perhaps the most interesting question) is what implications all this has and should have for economic theory. What follows from the fact that several crucial issues in neuroscience are still unresolved? That we as economists should wait until neuroscience has grown more mature before we try to accommodate their insights and findings? Or should we rather follow Neurath's dictum that in the process of mutual adjustments between disciplines there is no other option than to rebuild the ship from its own timbers at open sea? Furthermore, even if we did know everything there is to know about brain structure and brain functioning, including knowledge of what regions of the brain are activated by what sorts of environmental conditions, it would still not be clear what implications this should have for economic theory. There are at least two different takes on this. Following a suggestion made by Berns (2003), Ross argues that findings in neuroscience do not necessitate any revision of standard 
economic theory whatsoever. Ross does not deny that there is vast evidence that individual human behavior is irrational at least some of the time. But what this only suggests, Ross argues, is that not individual persons, but functionally specialized groups of neurons should be treated as rational economic agents. Thus, what should be changed is not standard economic theory, but our traditional idea that economic theory deals with the behavior of individual persons. Contrary to what is traditionally assumed in economics, the proper scope of economics would not be the behavior of individual persons and that of supra-individual entities such as organizations and industries, but the behavior of sub-personal systems in the brain.

The other take on what implications an imagined ideal neuroscience should have for economic theory retains the traditional idea that economic theory addresses phenomena that are located at higher levels of analysis than the phenomena addressed by neuroscience. One of the issues that this raises is how the various levels of analysis are related to each other. How is the behavior of (groups of) neurons and that of brain regions related to the behavior of individual persons, for example? Are there regular patterns in the ways in which the former map onto the latter? If so, what are these patterns? These are also open, unresolved issues. Gul \& Pesendorfer (2005) exploit the observation that neuroscience and economic theory address phenomena at different levels of analysis to argue that neuroscience does not and should not bear on economic theory. Economists are advised by Gul \& Pesendorfer to ignore neuroscience. I think this is overly defensive. It wrongly seems to assume that the levels of analysis are totally disconnected. Even if we do not fully understand yet how neural subsystems in the brain interact in producing behavior of individual persons and what roles environmental factors (including institutional ones) play in this, we do know that what is going on in the brain is connected somehow with individual human behavior and also with what happens at even higher levels of analysis. What can hardly be denied at any rate is that individual behavior produced in at least some contexts is not consistent with standard economic theory's predictions and that neuroscience is starting to shed light on this. This is something economists can only ignore at their own peril.

\section{Acknowledgements}

Useful and inspiring comments on an earlier draft by John Davis, Geoff Hodgson, Ulrich Witt, Paul J. Zak, participants of the Wartensee-workshop on evolutionary economics (organized by Kurt Dopfer) and participants of the Seminar jointly organized by Ecole Polytechnique, ENS Um, and University of Paris 1, as well as two anonymous referees, are gratefully acknowledge. The usual disclaimer applies. 


\section{Notes}

1. The focus of bioeconomics and neuroeconomics on the one hand and that of evolutionary game theory and evolutionary economics on the other need not exclude each other. In fact, Geoffrey Hodgson (1997); Hodgson (1998) and Ulrich Witt (1999, 2003) are examples of interesting attempts to incorporate the insight that human beings are evolved creatures in studies of ongoing processes of economic evolution.

2. Note that Tullock is not arguing here that application of standard economic theory's constrained maximization framework in biology necessarily leads to different results or insights. The main gain envisioned is increased simplicity in explanation.

3. Henceforth, I will use 'constrained maximization' and 'optimization' interchangeably.

4. See also "indeed, it could be argued that I have never left economics, that all my "biological" articles are simply economics articles in which I have rather unusual sets of entities maximizing a rather unusual utility function' (Tullock 1979, p. 2).

5. Ghiselin (1974, pp. 234-235) argues, for example, that Adam Smith failed to distinguish between competitive division of labor (between independent firms, for example) and cooperative division of labor (between members of the same firm).

6. When speculating about the possible implications of sociobiology for the discipline of economics, Edward O. Wilson (1977, p. 136) also notes that 'the graphical methods of economics', optimization and decision theory, have already been routinely used in ecology and sociobiology. See also Zak \& Denzau (2001) for an overview.

7. This may be a bit surprising to those who know Becker and Hirshleifer as staunch advocates of economic imperialism (or economics imperialism, Mäki 2002). Becker and Hirshleifer do believe that 'the economic approach' is superior to non-economic approaches in biology. But they also believe that in return biology could help economics overcome present limitations: instead of arbitrarily taking into account only the 'egoistic' parts of human nature, incorporating the effects of genetic selection (Becker 1976, p. 818 and p. 826) could help economics to identify 'the whole human being'. They think there is a need to do so to explain phenomena even in economics' traditional domain of market behaviour (Hirshleifer 1977a, p. 28).

8. See also 'where standard economics takes the satisfaction of preferences as the primitive objective or 'utility function' of the acting individuals, biological theory suggests that what seems like mere preference or taste evolves out of the objective dictates of reproductive survival' (Hirshleifer 1977a, p. 50). Robert Frank's (1988) work on emotional commitments and adaptive rationality (Frank 2004) seems to subscribe to this programmatic contention. By contrast, Witt (1991) argues that sociobiological arguments wrongly bypass innate learning mechanisms in forming preferences.

9. Note that this deviates from a standard interpretation of 'group selection' according to which kin selection and group selection are seen as two different routes via which altruism can evolve.

10. As Becker (1976, p. 824) himself observes, the concept of altruism that Edward O. Wilson and other evolutionary biologists are talking about is not the same as the concept Becker is discussing. In the helpful terminology of Sober \& Wilson (1998), while Edward O. Wilson is discussing evolutionary altruism (behavior that reduces personal fitness by definition, whatever the 'proximate causes' responsible for it), Becker is discussing psychological altruism (altruistic preferences, or the intention, or inclination to transfer part of one's own wealth to others).

11. Hirshleifer (1977b) rightly commented that for Becker's argument to be valid, Big Daddy needs to have the last word.

12. Since correct anticipations are also a crucial part in the explanation, it might be added that next to preferences and constraints, expectations also are a major determinant of human behavior.

13. Cf. Coase's (1978, p. 245) worry: 'The danger is that dabbling in sociobiology may prove to be more attractive to many economists than the use of sociobiological findings to improve our economics.' For Coase it is clear that the latter - using sociobiological findings to improve economics - should be aimed at. 
14. In 2005, The Society for Neuroeconomics (see http://www.neuroeconomics.org/index.htm) was founded.

15. Articles about neuroeconomics have appeared in several newspapers and newspaper magazines, such as The Wall Street Journal, The Economist, Newsweek, Forbes, The Los Angeles Times and The New York Times.

16. Simplifying a bit, one could say that the proximate causes of current behavior, the 'cogs and wheels' in the internal behavior-generating machinery, are the outcome of the behavior's ultimate causes (notably, natural selection).

17. Thus, the criticism levelled against sociobiology, that forces driving biological evolution other than natural selection (such as genetic drift) are not sufficiently paid attention to, also seem to apply to bioeconomics. The same holds for the criticism that culture and cultural evolution (as well as individual ontogenetic development, it might be added) are given short shrift in sociobiology.

18. Following Adam Smith, Ronald Coase $(1976,1978)$ (who should not be counted as a bioeconomist, but who does believe that there something to learn from evolution for economists and who did participate in the debates over sociobiology/evolutionary biology and economics in the 1970s) is more sceptical about the degree to which human behavior is guided by reason.

19. The brain's anatomy and physiology can themselves be regarded at two different levels of description in their own right.

20. As Zak (2004) rightly notes, for these neuroeconomists behavioral economics is at least as much the progenitor of neuroeconomics as bioeconomics.

21. The focus on these two groups is not meant to belittle important contributions to neuroeconomics made by other proponents of (and contributors to) neuroeconomics such as Kevin McCabe, Daniel Kahneman, Paul Zak, Aldo Rustichini, David Laibson, John Dickhaut, Wolfram Schultz, Ernst Fehr, James Rilling, Alan Sanfey, Antonio Rangel, Daniel Houser, Brian Knutson and many others.

22. See also: ' $\ldots$ desirability is realized as a concrete object, a neural signal in the human and animal brain, rather than as a purely theoretical construction' (Glimcher \& Rustichini 2004, p. 452).

23. To Glimcher, the human brain is not just part of economic systems. It is an economic system by and of itself with its own goals, constraints (metabolic costs in particular) and 'currency' (neural firing rates). I owe this observation to Paul J. Zak (personal communication). See also Ross (2006, 2007). For a similar treatment of the human brain as an economic system, see Robson (2001). See Vromen (2003) for a critique of Robson.

24. See also Kahneman's (2003) similar distinction between System 1 and System 2 type cognitive processes.

25. One could argue that the computations and calculations at the neural level described by Glimcher et al. are metaphorical. Or, alternatively, following Bennett \& Hacker (2003), we could say that Glimcher et al. commit a mereological fallacy here: only the individual organism (such as a human being) as a whole can be the proper subject of psychological attributes involved in processes such as calculations, not any of its parts (such as neurons).

26. This is what Kacelnik (2006) calls 'E-rationality' (rationality as conceived of by economists). Kacelnik argues that whereas economists prefer to be agnostic about the processes in which behavior is produced, for psychologists and philosophers (who entertain 'PP-rationality') behavior can only be rational if the behavior is produced in reasoning processes that meet certain conditions.

27. It might be added here that, conversely, 'rational behavior' in the sense of consciously pre-meditated behavior might well be 'irrational behavior' in the sense of behavior that is inconsistent with standard economic theory's predictions. The simple reason or this is that people who do their utmost best in solving a maximization problem (or in attaining optimal results), for example, can fail.

28. As Dawkins (1995) argues, the utility function in question is DNA (or gene) survival. As Dawkins himself notes that this may imply inefficiency, it is perhaps a bit misleading of Dawkins to talk of God's utility function here.

29. It is ' ... more a hypothesis for testing rather than anything certain' (Glimcher 2002, p. 327). 
30. It seems (and perhaps this is symptomatic for the mutual misunderstandings that plague the neuroeconomics movement) that Camerer et al. want to raise this point as an objection against Glimcher et al., whereas they are in fact fully in agreement on this point.

\section{References cited}

Becker, Gary S. 1976. Altruism, egoism, and genetic fitness: economics and sociobiology. Journal of Economic Literature: $817-826$.

Bennett, Max R. \& Peter M. S. Hacker. 2003. Philosophical foundations of neuroscience. Blackwell, Oxford.

Berns, Gregory S. 2003. Neural game theory and the search for rational agents in the brain. Behavioral and Brain Sciences 26(2): 155-156.

Camerer, Colin F. 2003a. Behavioral game theory: experiments in strategic interaction. Princeton University Press (Russell Sage Foundation), Princeton, New Jersey.

Camerer, Colin F. 2003b. Strategizing in the brain. Science 300: 1673-1675.

Camerer, Colin F. 2005. Neuroeconomics: what is neuroeconomics? (Found on: http://www.hss.caltech. edu/ camerer/web_material/n.html. Consulted May 2005).

Camerer, Colin F., George Loewenstein \& Drazen Prelec. 2004. Neuroeconomics: why economics needs brains. Scandinavian Journal of Economics 106(3): 555-579.

Camerer, Colin F., George Loewenstein \& Drazen Prelec. 2005. Neuroeconomics: how neuroscience can inform economics. Journal of Economic Literature 43(1): 9-64.

Chorvat, Terence R. \& Kevin McCabe. 2005. Neuroeconomics and rationality. Chicago-Kent Law Review 80: 101-121.

Coase, Ronald H. 1976. Adam Smith's view of man. Journal of Law and Economics 19: 529-546.

Coase, Ronald H. 1978. Comment (on Ghiselin 1978). American Economic Review (Papers and Proceedings) 68: 244-245.

Dawkins, Richard. 1995. God's utility function. Pp. 111-155 in River out of Eden. Phoenix, London.

Dopfer, Kurt. 2005 (ed.) The Evolutionary Foundations of Economics. Cambridge University Press, Cambridge.

Frank, Robert H. 1988. Passions within reason. W.W. Norton \& Company, New York.

Frank, Robert H. 2004. What price the moral high ground? Ethical dilemmas in competitive environments. Princeton University Press, Princeton.

Ghiselin, Michael T. 1974. The economy of nature and the evolution of sex. Berkeley and Los Angeles. University of California Press, California.

Ghiselin, Michael T. 1978. The economy of the body. American Economic Review (Papers and Proceedings) 68: 233-237.

Gigerenzer, Gerd, Peter M. Todd \& ABC Research Group. 1999. Simple heuristics that make us smart. Oxford University Press, New York/Oxford.

Glimcher, Paul W. 2002. Decisions, decisions, decisions: choosing a biological science of choice. Neuron 36: 323-332.

Glimcher, Paul W. 2003. Decisions, uncertainty, and the brain: the science of neuroeconomics. The MIT Press, Cambridge.

Glimcher, Paul W. \& Aldo Rustichini. 2004. Neuroeconomics: the consilience of brain and decision. Science 306: 447-452.

Glimcher, Paul W., Michael C. Dorris \& Hannah M. Bayer. 2005. Physiological utility theory and the neuroeconomics of choice. 52: Games and Economic Behavior 213-256.

Gul, Faruk \& Wolfgang Pesendorfer. 2005. The case for mindless economics (Working paper, http://www.dklevine.com/archive/refs4784828000000000581.pdf).

Hirshleifer, Jack. 1977a. Economics from a biological viewpoint. Journal of Law and Economics: 1-52. 
Hirshleifer, Jack. 1977b. Shakespeare vs. Becker on altruism: the importance of having the last word. Journal of Economic Literature: 500-502.

Hirshleifer, Jack. 1978. Competition, cooperation, and conflict in economics and biology. American Economic Review (Papers and Proceedings) 68: 238-243.

Hodgson, Geoffrey M. 1997. The ubiquity of habits and rules. Cambridge Journal of Economics 21(6): 663-684.

Hodgson, Geoffrey M. 1998. The approach of evolutionary economics. Journal of Economic Literature 36(1): 166-192.

Hodgson, Geoffrey M. 2000. Evolution and institutions: on evolutionary economics and the evolution of economics. Edward Elgar, Cheltenham.

Kacelnik, Alex. 2006. Meanings of rationality. Pp 87-106 in S. Hurley \& M. Nudds (ed.) Rational Animals? Oxford University Press, Oxford.

Kahneman, Daniel. 2003. Maps of bounded rationality: psychology for behavioral economics. American Economic Review 93(5): 1449-1475.

Kysar, Douglas A. (Rapporteur). 2006. Group report: are heuristics a problem or a solution? Pp. 103140 in C. Engel \& G. Gigerenzer (ed.) Heuristics and the Law. MIT Press, Cambridge. (Other participants: Peter Ayton, Robert H. Frank, Bruno S. Frey, Gerd Gigerenzer, Paul W. Glimcher, Russell Korobkin, Donald C. Langevoort \& Stefan Magen.)

Landa, Janet T. \& Michael T. Ghiselin. 1999. The emerging discipline of bioeconomics: aims and scope of the Journal of Bioeconomics. Journal of Bioeconomics 1: 5-12.

Landa, Janet T. \& Xiao T. Wang. 2001. Bounded rationality of economic man: decision making under ecological, social, and institutional constraints. Journal of Bioeconomics 2001(2-3): 217-235.

Loasby, Brian J. 1999. Knowledge, institutions, and evolution in economics. Routledge, London.

Mäki, Uskali. 2002. Explanatory ecumenism and economics imperialism. Economics and Philosophy 18(2): 235-257.

Marr, David. 1982. Vision: a computational investigation into the human representation and processing of visual information. Freeman, San Francisco.

Maynard Smith, John. 1982. Evolution and the theory of games. Cambridge University Press, Cambridge.

Mayr, Ernst. 1961. Cause and effect in biology. Science 134: 1501-1506.

Metcalfe, Stanley. 1998. Evolutionary economics and creative destruction. Routledge, London.

Montague, P. Read \& Gregory S. Berns. 2002. Neural economics and the biological substrates of valuation. Neuron 36: 265-284.

Nelson, Richard R. \& Sidney Winter. 1982. An evolutionary theory of economic change. Harvard University Press, Cambridge.

Powell, Kendall. 2003. Economy of the mind. PloS Biology 3: 312-315.

Platt, Michael L. \& Paul W. Glimcher. 1999. Neural correlates of decision variables in parietal cortex. Nature 400(6741): 233-238.

Robson, Arthur J. 2001. Why would nature give individuals utility functions? Journal of Political Economy 109: 900-914.

Rosenberg, Alex. 2005 Lessons from biology for philosophy of the human sciences. Philosophy of the Social Sciences 35(1): 3-19.

Ross, Don. 2006. The economic and evolutionary basis of selves. Cognitive Systems Research 7: 246-258.

Ross, Don. 2007. Integrating the dynamics of multi-level economic agency. In H. Kincaid \& D. Ross (ed.) Oxford Handbook Philosophy of Economics. Oxford University Press, Oxford (forthcoming).

Samuelson, Larry. 1997. Evolutionary games and equilibrium selection. MIT Press, Cambridge.

Schweber, Silvan S. 1968. Darwin and the political economists: divergence of character. Journal of the History of Biology 13: 195-289.

Smith, Vernon. 2003. Constructivist and ecological rationality in economics: Nobel Prize Lecture 2002. American Economic Review 93(3): 465-508. 
Sober, Elliott \& David Sloan Wilson. 1998. Unto Others: the evolution and psychology of unselfish behavior. Harvard University Press, Cambridge.

Tullock, Gordon. 1971a. The coal tit as a careful shopper. The American Naturalist 105: 77-80.

Tullock, Gordon. 1971b. Biological externalities. Journal of Theoretical Biology 33: 379-392.

Tullock, Gordon. 1979. Sociobiology and economics. Atlantic Economic Journal: 1-10.

Vromen, Jack J. 1995. Economic evolution: an enquiry into the foundations of new institutional economics. Routledge, London.

Vromen, Jack J. 2003. Why the economic conception of human behavior might lack a biological basis. Theoria 48: 297-323.

Vromen, Jack J. 2004a. Conjectural revisionary economic ontology: outline of an ambitious research agenda for evolutionary economics. Journal of Economic Methodology 11(2): 213-247.

Vromen, Jack J. 2004b. Taking evolution seriously: what difference does it make for economics? Pp. 102131 in J. Davis, A. Marciano \& J. Runde (ed.) The Elgar Companion to Economics and Philosophy. Edward Elgar, Cheltenham.

Weibull, Jürgen W. 1995. Evolutionary game theory. MIT Press, Cambridge.

Wilson, Edward O. 1975. Sociobiology: the new synthesis. The Belknap Press of Harvard University Press, Cambridge.

Wilson, Edward O. 1977. Biology and the social sciences. Daedalus: 127-140.

Wilson, Edward O. 1998. Consilience: the unity of knowledge. Alfred A. Knopf, New York.

Witt, Ulrich. 1991. Economics, sociobiology, and behavioral psychology on preferences. Journal of Economic Psychology 12: 557-573.

Witt, Ulrich 1999. Bioeconomics as economics from a Darwinian perspective. Journal of Bioeconomics 1: $19-34$.

Witt, Ulrich. 2003. The evolving economy: essays on the evolutionary approach to economics. Edward Elgar, Cheltenham.

Young, H. Peyton. 1998. Individual strategy and social structure: an evolutionary theory of institutions. Princeton University Press, Princeton.

Zak, Paul J. 2004. Neuroeconomics. Philosophical Transactions of the Royal Society of London Series B 359: 1737-1748.

Zak, Paul J. \& Arthur T. Denzau. 2001. Economics is an evolutionary science. Pp. 31-65 in S. A. Peterson \& A. Somit (ed.) Evolutionary Approaches in the Behavioral Sciences: Toward a Better Understanding of Human Nature. Elsevier Science, Amsterdam.

Zak, Paul J. \& Stephen Knack. 2001. Trust and growth. The Economic Journal 111(470): 295-321. 